\title{
Singing and playing music through mobile applications: Smule, a new music experience
}

\author{
Madeleine Le Bouteiller
}

\begin{abstract}
Mobile phones and the Internet combined have led to the creation of applications that allow their users to perform music using only their Smartphones. With the Smule applications that we analyze in this paper, people can sing karaoke together with other singers from all over the world, or play a tune with their fingertips tapping on a phone's screen. Besides providing new entertainment activities, the Smule applications and their multiple options regarding audio and video editing can bring about new musical practices and musical artifacts. Smule users can sing duets remotely, without actually singing on the same time - a virtual collective performance. Singing karaoke becomes a solitary practice where togetherness is contrived but not achieved. Video recordings can be edited and shared on a built-in social network, thus being endorsed with a new function: to create bonds within a social network. Analyzing the discourses of Smule creators and developers, we also show that the applications do not achieve what they are promised to do, namely providing social and authentic practices.
\end{abstract}

Keywords: Internet, mobile applications, remote music performances, karaoke. 


\section{Résumé}

Grâce à Internet, les téléphones portables donnent accès à des applications permettant aux utilisateurs de chanter et jouer de la musique avec leur Smartphone. L'entreprise Smule distribue des applications pour chanter en karaoké avec d'autres à distance, ou jouer un air du bout des doigts sur l'écran du téléphone. En plus de fournir du divertissement, ces applications et leurs options d'édition audio et vidéo, donnent lieu à de nouvelles configurations musicales et de nouveaux artéfacts. Le karaoké devient une pratique solitaire où le «être ensemble » n'est pas accompli mais feint à travers le montage vidéo. Les enregistrements bénéficient de traitements audio et vidéo et sont ensuite partagés sur le réseau social de Smule, ce qui leur confère une fonction particulière, celle de créer des liens au sein du réseau. Par l'analyse des discours émanant des créateurs et développeurs de Smule, nous montrons finalement que ces applications ne réalisent pas toujours les promesses qu'on leur prête, à savoir donner lieu à des pratiques sociales et authentiques.

Mots-clés : Internet, applications mobiles, performances musicales à distance, karaoké

\section{Introduction}

What can a smartphone and Internet do to music? Some applications make it possible to join musicians from all over the world to sing, play music, record it and share it, all this using only Smartphones. Smule is a company that created several applications for singing karaoke and playing guitar or piano on a smartphone's screen. Typing onto the screen with a few fingers makes you play guitar; you can make a karaoke duet with someone on the other side of the world, you can edit and share your recordings on the built-in social network that Smule also provides.

Playing, consuming, sharing music are all being redesigned through these applications. How turning existing musical activities (singing karaoke, 
playing musical instruments) into mobile applications can transform these practices? Our hypothesis is that the Smule applications lead to the production of a new sort of musical practices and musical objects. To test this hypothesis, we will analyse the possibilities brought about by the Smule applications and examine the sorts of musical objects and practices that can arise through the use of these applications. After examining the practices resulting from the use of the Smule applications, as well as the musical entities being produced, and evaluating how much these practices and objects differ from traditional musical situations (karaoke settings, concerts, and performances) and recordings, we will be able to confirm or rebut our hypothesis. Additionally, we will compare our findings with the discourses about Smule coming from its founders and developers so as to pinpoint a possible discrepancy between what Smule was promised to do and what it really does.

Our investigations are based on the ontology of music as developed by the analytic philosophers of the recent times, starting with Nelson Goodman and especially Stephen Davies for his accounts on musical works (Goodman 1976; Davies 2001). Regarding music performances, we draw on the works of Stan Godlovitch and Erika Fischer-Lichte (Godlovitch 1998; FischerLichte 2008). As the core of the tradition in the philosophy of music often focuses on the notion of musical works (as well as the notion of performance, although more recently), we will draw on this tradition, but we will also have to resort to the notion of musical object or artifact. For this, we will relate to the work of Alessandro Arbo (Arbo 2010) and Marcello Ruta (Arbo and Ruta 2014). The philosophy of Roger Pouivet will also help us to explain the status of musical recordings in our case (Pouivet 2010).

The Smule company was founded in 2008 in the San Francisco Bay area by Jeff Smith and Ge Wang. It started with the release of a few applications - among them the notorious Ocarina, that "turns an iPhone into a musical instrument". Today ${ }^{3}$, Smule supports five different applications, available on

\footnotetext{
${ }^{3}$ As of February 2020.
} 
Google Play and/or on the App Store: the eponymous application Smule (formerly called Sing! karaoke), AutoRap, Magic Piano, Magic Guitar, and Ocarina.

The Smule applications are indeed worth considering. First, because they are widespread and are likely to spread even more - especially the karaoke application, which has been downloaded over a hundred million times to this day. It exists in 49 different languages; it has 52 million monthly active users, and the number of users keeps growing 4.300 million people in total have used the Smule applications ${ }^{5}$. Second, because to our knowledge, the impact they can have on musical and social practices has not yet been addressed.

In this paper, we will explore the Smule applications so as to identify the main changes they bring about, in the practices as well as in the musical artifacts that can be produced with them. Several dimensions will be examined: making and performing music, sharing and consuming, the kind of objects that are produced, and how these objects are being used - their function. We will also examine how the discourses surrounding the Smule applications (in advertisement, in magazines, or scientific papers) reflect in the reality. This case study will lead us to highlight the new musical objects and practices that emerge through the use of these applications - some that do not necessarily match the discourses promoting them. We will first explore the karaoke and instrumental applications, with their different features and affordances. We will then examine Smule's social network and its impact on musical practices, and finally analyze how the narratives about Smule are confirmed or contradicted in reality.

\footnotetext{
${ }^{4}$ See the Smule page on Apple's app Store: https://apps.apple.com/us/app/smule-the-socialsinging-app/id509993510 (accessed in February 2020).
Business
Wire,
2015 [online]. https://www.businesswire.com/news/home/20151029005392/en/Sing!-Karaoke-SmuleApple-TV-Brings-Home (accessed in February 2020)
} 


\section{Smule, the applications}

\subsection{Singing karaoke with a smartphone}

The Sing! karaoke application, launched in 2012 and later renamed Smule, is by far the most popular of the five. It provides a karaoke environment on the smartphone. Lyrics and pitch lines are displayed on the phone or tablet's screen and stream as the song goes on (Fig. 1). Singers follow the indications and can record their performance, both audio and video. Smule provides a catalog of 10 million tracks to which the users can sing along to. Users can pay for a subscription to have access to the full library, or use the application for free and have only access to a limited number of songs ${ }^{6}$.

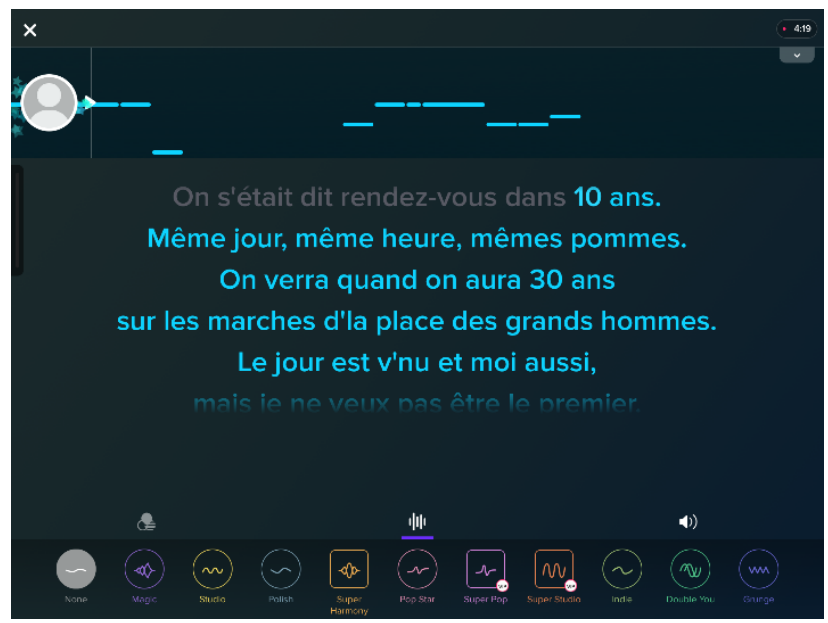

Fig. 1. Screenshot of Smule during a karaoke session on

Patrick Bruel's song Place des Grands Hommes

A number of voice treatment options are available. At the bottom of the screen, singers can pick studio effects and voice filters to enhance their voice, such as an autotune or various types of reverberation (Fig. 1). Some studio effects, like the autotune, are only available to VIP members (users who pay for a subscription). These effects can be used on the fly while singing or after

\footnotetext{
${ }^{6}$ A one-week subscription is $9,99 €$. One can also pay $19,99 €$ for a month or $99,99 €$ for a year.
} 
the song has been completed, before saving the recording. Multi-take recording is also possible: one can go back and forth in the song to record a passage again, without having to start again from scratch.

Once the video is recorded and edited, Smule users can choose between private or public release. In the former case, the singer chooses who to share the video with. Otherwise, the recording becomes available on the mobile application as well as on Smule's webpage ${ }^{7}$ where anyone can watch it, without needing a Smule account. As soon as a song is being recorded and uploaded in public mode, it becomes automatically visible on the application as well as on this webpage - to the whole world.

When deciding to record a song, the user can choose between singing it alone, in a duet or in a group. With the duet option, the singer records half of the track. Then, other users are invited to sing the second part of the song or, conversely, one can sing a karaoke on a backing track onto which someone who has already recorded half of the song ${ }^{8}$. The same applies for group singing. On the final video, we can see the two singers, alternately or side to side, singing in turn and sometimes together. The two have sung at different times and in different locations, but their images and their vocals are being assembled into a single video recording. Practically, one can also record a duet with oneself, leading to paradoxical videos where one same person appears in duplicate, the two faces singing different lines, side by side.

Renowned artists have joined the Smule network. They have provided an arrangement of their own song and a video recording where they sing half of it. In the feature called "sing with the artist", Smule members have the opportunity to sing the second part of the song, where the first part has been recorded by a professional singer - or with a Disney character, when the song

\footnotetext{
${ }^{7} \mathrm{https}: / /$ www.smule.com/ This web interface is provided by Smule for a consultative usage only. The most popular songs appear first, sorted by categories (most popular, Disney, French songs, 1980s...).

${ }^{8}$ Joining a duet is free for all Smule members, even without a subscription. To start a duet, only VIP members can access the full catalog of sons.
} 
comes from a Disney movie soundtrack. One can sing while watching the other singer singing on the video. This can create a feeling of simultaneity whereas the two singers have never been singing at the same time. This feature is very popular. For instance, the Smule repertory holds 1.6 million of collaborations on the song Despacito by Luis Fonsi, sung in a duet by Fonsi himself and Smule users. Of course, Fonsi has recorded the song only once, and everyone can join his recording to complete the song, record it and release it.

Singing karaoke is not a new thing. Karaoke is a musical practice that appeared in Japan in the 1960s. The word comes for the Japanese "karappo" (empty) and "okesutura" (orchestra) - to be understood as an orchestra recording void of vocals (Mitsui \& Hosokawa 1998). It is a collective entertainment, especially adapted to pop songs where the vocals can easily be separated from the musical accompaniment. People gather together in bars or at home and enjoy singing along to their favorite tunes, in turn or all together. It is a collective practice of entertainment.

But the Smule karaoke application offers something different. First of all, karaoke singing becomes accessible anytime and anywhere (provided an Internet connection and a smartphone): no more need to organize a social gathering. A smartphone and a simple headset are enough to start a karaoke session at home or anywhere - a lighter and easier set up than a TV, big speakers and microphone would be. Second, when users engage with Smule, most of the time they sit at home, alone in their room; they grab a phone or a tablet, pick a song and perform it on their own. Karaoke becomes a solitary practice. Smule singers either complete the whole song on their own, or they join someone (or are being joined by someone) to complete the other half of the song. In both cases, karaoke singers remain alone at home. They are actually never singing together: neither on the same place, neither on the same time. In a duet or group recording, the collaboration is delayed in time. People are actually not engaging with one another, but pasting two recordings in a common video. 
We can often observe that singers try to make up for this non-togetherness. Fonsi himself, in his recording of Despacito, sometimes glances off-camera, to the side where he knows the second singer will appear on the video. $\mathrm{He}$ speaks to this absent singer; and sometimes, the collaborators of this duet play the game: they look off-camera to the side where Fonsi's video will eventually appear. They actually look at nobody, but know that in the end, it will look as if the two singers look at each other. This game-playing is noteworthy as it emphasizes the absence of live collaboration between the two singers, who are trying to make up for it, contriving a virtual co-presence.

Unlike an original karaoke singing, Smule singers not only sing for entertainment, but also strive to obtain a good recording of their singing. Multi-take recording and voice treatment studio effects help to provide a polished recording of one's interpretation of a song. Therefore, Smule's karaoke singing deviates slightly from its original form. Not only the action (singing) is valued, but also the object being produced out of it: the video, which is not a pure testimonial recording of the action but is an artifact, an object that has been worked on with a purpose.

What sort of musical object is this recording? At first sight, one could think that it is a testimony of an event, one person singing to a backing track - a witness-recording of a performance, of an event that happened at one specific time and place. But because of the editing and processing options, it is more than often not the simple recording of an event but an object that has been worked on (with multi-take recording, sound processing, and assemblage of two or more vocals). Even though these processing steps are not as developed as they would be in a real recording studio, we contend that it has an impact on the nature of the recording. Additionally, when it is a duet or group recording, the result is a mashup of several performances that have happened at different times and places. This deepens the gap between a testimony recording and a recording produced as a musical object for its own sake. The distinction between these types of recordings has been developed and analysed by Roger Pouivet (Pouivet 2010). In his ontology of musical works, 
the studio recording of a musical piece as first performed by rock bands is a new sort of musical work, a work that is fixed on a support (a vinyl, a disc, a digital support...). However, unlike the rock recording as accounted for by Pouivet, the Smule recordings are not considered to be musical works. We will come back to this point later in the paper.

\subsection{Live duets}

Let us finally mention a feature that was launched in the summer of 2018 , called LiveJam ${ }^{9}$. In this feature, people join and connect together to sing a duet in real time and broadcast it live, on the application as well as on the webpage. VIP members can host a live jam, and everyone can join. One has to wait on a list of people who, in turn, sing a duet with the hosting person. A LiveJam session is either public or private. In the latter case, only the invited guests can attend the session. Public LiveJam sessions are broadcast on the website and on the application, visible to anyone ${ }^{10}$. One can see two people greeting each other, deciding on a song, and singing it together. They see each other through the video and hear each other in real time.

In this setting, the simultaneity problem seems to be solved: people are really singing on the same time ${ }^{11}$. They are singing together: the same song, on the same time, but in different locations. Visual contact is limited to what one can show through the smartphone's camera and screen. The collective practice of singing karaoke is therefore realized in a new way: singing together is reduced to seeing the singing partner through the screen and during the time of the song (plus the time to agree on a song). The members of the audience appear under their pseudonym and profile picture, they can write

\footnotetext{
${ }^{9}$ LiveJam has been replaced by another feature, Sing Live, since the summer of 2020.

${ }^{10}$ The new version of LiveJam, Sing Live, is only accessible to VIP members. Additionally, they have to belong to a group, and the live sessions can only happen among one group.

${ }^{11}$ A delay might nonetheless exist: one singer can hear the other one's vocals with a slight delay. In such case, Smule recommends the singers to follow the backing track and not their partner's singing to be on time. The problem is solved on the recording - if it is being saved.
} 
messages to the group of singers and attendees. Participation of the public exists through the use of written messages where attendees can chat and comment on the performance of the singers.

The Smule karaoke application leads therefore to a new sort of musical practice. It is a collective musical practice, it is a performance, but a performance where interactions between musicians and between musicians and their audience are redesigned. The "co-presence" of performers and audience, introduced as an essential characteristic of a performance by Erika Fischer-Lichte (Fischer-Lichte 2008) as well as by Stan Godlovitch (Godlovitch 1998) is not fully realized, but arises with a variation, since it is not any more an action happening "here and now" but "everywhere and now", with performers and an audience sitting in different places of the world. However, this is not specific to Smule. As early as 1998, Atau Tanaka and Kasper T. Toeplitz created an installation, Global String, on which they can perform music together while being in two different cities (Tanaka and Bongers 2003). But the situation created by Smule is an innovation in the sense that it makes it accessible to anyone (provided a Smartphone and a connection to the Internet) to sing with anyone in the world, at any moment. And the most prominent novelty is that it transforms the karaoke tradition into a practice where people do not need to gather in one same place to perform together.

\subsection{Instrumental applications}

Apart from the karaoke application, Smule develops other musical applications that can fall under the "instrumental" category: Magic Guitar, Magic Piano, and Ocarina.

Magic Guitar offers its users to 'play' guitar: the left finger selects the chord (by touching one colored box one among a few), the right thumb picks the strings by touching them on the screen (Fig. 2a). The patterns stream from left to right on the screen, the user has to follow the shape and color 
indications to play the song right: the right chords and the right notes from the chord. Magic Guitar offers to play songs where vocals are prerecorded. The player triggers the notes that have to be played in the instrumental accompaniment by touching the strings.

Magic Piano is a very similar application: tracks are prerecorded, and a piano roll appears on the screen. The user "plays" the notes by touching the screen at the right place at the right moment, where the colored dots meet the line (Fig. 2b).
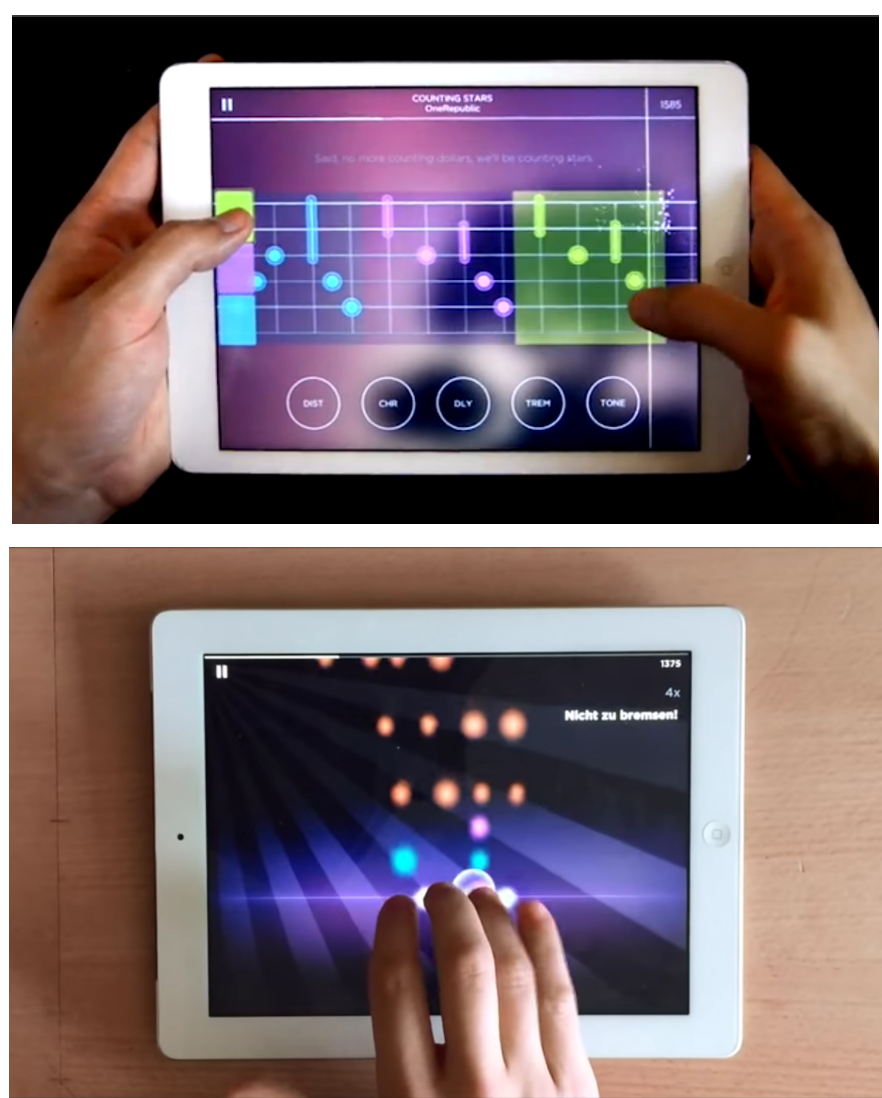

Fig. 2. Magic guitar being played on a tablet (top) ${ }^{12}$. The left thumb activates the chord changes following the color indications and the right thumb triggers the notes by touching the strings. The magic piano (bottom) ${ }^{13}$.

\footnotetext{
${ }^{12} \mathrm{https}: / / \mathrm{www}$. smule.com/apps.

${ }^{13} \mathrm{https} / / /$ www.youtube.com/watch?v=RQTTuaY6E7Q (accessed in February 2020).
} 
Ocarina was the first long-standing application released by the Smule company. Making use of most of the affordances of the iPhone (multi-touch screen, microphone, speaker, GPS, tilt sensors), it "transforms the iPhone into an ancient flute-like instrument ${ }^{14}$ ". To play Ocarina, one has to blow into the iPhone's microphone (Fig. 3). The fingers touch the screen on the dots to cover the ocarina's "holes" and produce different notes. Tilting the phone creates a vibrato. The application provides scores under the form of tablatures that indicate the finger position series to be executed in order to interpret a song.

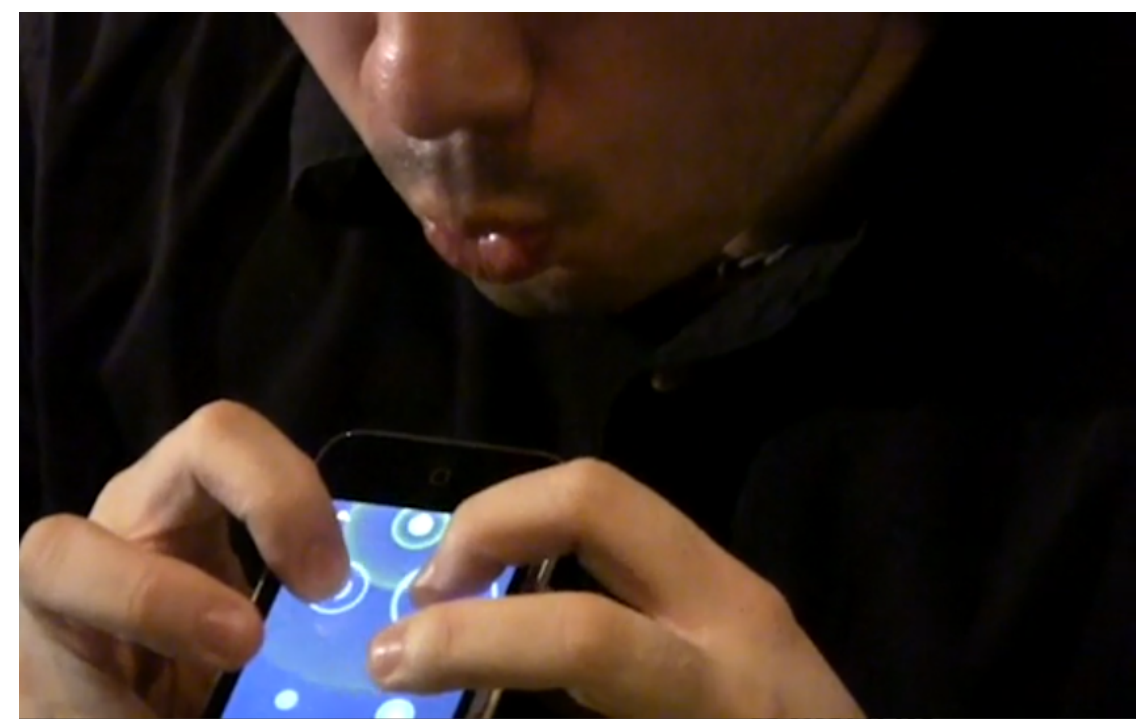

Fig. 3. The ocarina application ${ }^{15}$.

Smule's “instrumental” applications, Magic Piano, Guitar and Ocarina, allow anyone, musician or not, to easily play a tune or a song on a smartphone or tablet. Following the indications about when and where to place the fingers on the screen is enough to get a correct result - to be in tune and in rhythm. The entry level is accessible to anyone; with experience and training, one can

\footnotetext{
${ }^{14}$ From the advertisement video for Ocarina, on https://www.smule.com/apps (accessed in February 2020).

${ }^{15}$ Ibid.
} 
aim at higher level songs that require dexterity and a good coordination especially for Magic Piano and Magic Guitar. One could therefore ask: do these applications turn the smartphone into a musical instrument or do they come closer to video games, the output of which is a musical content?

Songs have different difficulty levels. The aim to complete a song is to follow the indications correctly and on time. One has to comply with the instructions; there is not much roam for artistic interpretation. On Magic Guitar, the user has the possibility to play another string than the one indicated, at any time. The note remains in the correct chord. To play other notes (another chord), one has to pick with the left finger another color than the one indicated. This gives the possibility to play in advance one of the next chords to come, but not to freely decide what note or chord to play. Magic Guitar is therefore far from real guitar playing; it rather classifies as a video game. The same applies to Magic Piano.

It goes somehow differently with Ocarina: within a given tessitura and tuning system, players have the freedom to play the notes they want, without following a chart. Ocarina players can then play any tune, and not prerecorded songs. Freedom is therefore larger than it is with Magic Guitar or Piano. Ocarina stands closer to a musical instrument, and the statement: Ocarina "transforms the iPhone into an ancient flute-like instrument ${ }^{16 "}$ sounds rather true.

Let us now mention the fifth Smule application, AutoRap. It turns speech into a rap song, by setting the spoken words to a beat. Creativity, personal involvement, and progression are very limited. Possibilities are not as broad as they can be for the other applications. AutoRap has therefore less success and less impact than the other Smule applications. It is rather toy application, used for fun but not for a long-standing practice.

\footnotetext{
${ }^{16}$ From the advertisement video for Ocarina, on https://www.smule.com/apps.
} 


\section{Smule, a social network}

Smule is not only a set of musical applications, from karaoke to alternative musical instruments. It also comprises a built-in social network (Boyd \& Ellison 2007). All users have a pseudonym and a profile picture. They can establish connections by "following" other Smule members (bonds are therefore not necessarily mutual). Everyone's social network is visible. The profile of Smule members is public, it displays the list of the recordings they have done and uploaded. Smule members can "love" and comment other's recordings. They can chat through a messaging system. Groups allow users to connect with people with the same musical interests.

The different applications can be used collaboratively: one can play a tune on the guitar or the piano to accompany a singer's recording, and thus produce a mixed performance, that will be released on the social network. This possibility is nevertheless little used. The karaoke application is still the most successful and by far the most used, and the vast majority of the recordings uploaded on the Smule network are done by singers.

After having sung a song, users are invited to give feedback about whether or not they liked the arrangement of the song. Immediately comes a proposition to "follow" the person who uploaded the arrangement, and, in case of a duet, the singing partner of that duet. In Smule, everything is done to increase the connections within the network, encouraging people to create more bonds.

Smule members can collaborate to the expansion of the song catalog: users themselves can provide their own arrangement of a song, comprising a backing track, lyrics, and if need be, indications for a duet (the splitting of the song for two singers). Ocarina's catalog is also collaborative. Scores can be created and uploaded to the library by Smule members themselves. Smule's repertoire can therefore expand thanks to its members.

Additionally, Smule features a "global view", a dynamic view of the Earth that displays where on the world the most recent recordings have been 
uploaded. Ocarina has its own global view where one can not only see where people play or have played, but can even listen in real time to other people playing, from anywhere in the world. All people currently playing appear as little lights on the globe. One can click on one of them and listen to what this person is playing, in real time.

Smule being a social network, additionally to providing musical applications, has an impact on the status of its musical productions. Unlike the rock recording, which constitutes a musical work (Pouivet 2010), the Smule recordings do not aim to be works of art. To back this assertion, one could first say that Smule users are, most of them at least, not professional singers, and that singing on Smule is an entertaining activity addressed to all people, regardless of their musical skills. Also, the application determines a lot about the recording (the backing track, the video setting), making every Smule video easy to identify as such. But not only the level of the singers should be considered to claim that recordings are not musical works. What is also missing is the necessary activation so as to consider something a work of art (Goodman 1976). According to Nelson Goodman, the activation is the process through which an object can become a work of art and be considered as such: for a frame, being hanged on a museum wall, for a piece of music, being labeled and listened to as such. But the Smule recordings are published withing the application and website, among countless other recordings. They are in the first place addressed to other Smule users, even though some of them can also be published on other platforms (like YouTube).

It is therefore important to discuss the function of these recordings. They are not activated as musical works, but they have an important function within Smule. All users have a profile where their pseudonym and picture are followed by a list of the songs they have recorded, accompanied by the number of reads, "loves", and comments for each of them. Recordings are, first of all, the result of their attempt to interpret a song. As we have discussed before, it is not strictly a recording witnessing a performance, but a recording that may have been worked on (with multi-take and studio effects). We can 
also notice how people take care of their visual appearance on the videos: clothes, makeup and hairstyle, attitude, very often seem to be taken care of. This shows an awareness of being visible - once the video is uploaded. These recordings are displayed on the profile page of the Smule singers ${ }^{17}$. Smule members can like, comment, and share other's recordings.

Smule creates this unique configuration where recorded songs become the building blocks of a social network ${ }^{18}$. We have shown that the function of these recordings is not to keep memory of an event (a performance), nor to become a work of art, but it is to build the identity of Smule users - in order to, ultimately, contribute to the Smule network. Smule singers discover each other through the recordings made available on their profile. This utilisation of the videos is very specific to Smule. Consequently, on Smule, one sings not only for one's own fleeting enjoyment but also with the aim of getting visibility and gaining popularity, by posting a recording and collecting comments and "loves". Singing with Smule is for fun and for fame.

\section{Goals and deviations}

It is straightforward to affirm that Smule is oriented towards entertainment a musical entertainment. Smule's stated aim is to provide everyone, regardless of their musical training, with the opportunity to play music: "At Smule, we create social music-making experiences for everyone, no talent required ${ }^{19}$ ". Indeed, the karaoke application allows anyone to sing, with the possibility of producing a video recording of a satisfying quality with very little technical gear.

\footnotetext{
${ }^{17}$ Videos can also be shared on other networks, such as Facebook, Instagram, YouTube.

${ }^{18}$ If we think of other networks: the building blocks of Twitter are short texts. On Instagram, they are pictures or videos. On Facebook, they can be many things such as text, pictures, videos, polls... On Smule, users share one specific type of videos.

${ }^{19}$ https://www.smule.com/jobs (accessed in February 2020).
} 
When analyzing the narratives that surround the Smule applications (magazine articles, presentation and advertisement discourses, considered to be representative of the ideas and ambitions of Smule's creators and leaders), we can notice that social experience and authenticity are two major ideas often put forward to characterize Smule. Ge Wang, one Smule's creators, describes it as "a start-up company creating technology and experiences to explore social music making" (Wang 2014). To him, Smule is a platform allowing for "sonic-based social community building" (Wang 2009). Jeff Smith, Smule's co-creator and current CEO, bears out the idea: "We're a social network that's as much about creation as consumption. It's not a karaoke company per se: we're building a network around music and performance" ${ }^{20}$. He also declared: "We wanted to bring music back to its social roots" 21 . Smule's creators and leaders' discourses about their applications mention the social experience as a key idea. The Ocarina application, in its presentation video, is described not only as an instrumental application, but also as providing "a social experience" - principally through the global view. But is listening to a person's playing what we can call a social experience? The listener practically hears a tune or some notes being played by an unknown person somewhere in the world. But one has to keep in mind that the sound is actually played by their own iPhone: it replicates the notes played by the other Ocarina player. The person who plays does not know that they are being listened to. There is no other sort of communication between the two. In other words, the social side of the Ocarina experience is very limited. Of course, several people can gather together, with their phones, to play something together - as it has been well advertised with a video where a

\footnotetext{
${ }^{20}$ Dredge, Stuart, "Smule talks music apps, Jessie J, subscriptions and songwriters", in: Musically [online], $2^{\text {nd }}$ July 2015.

${ }^{21}$ CNBC 2018 [online] https://www.cnbc.com/2018/03/30/this-computer-music-phd-wantsto-connect-the-world-through-mobile-karaoke.html.
} 
guitarist and several Ocarina players interpret the song Stairway to Heaven ${ }^{22}$. But this configuration is not specific to, nor created by the Ocarina application.

The social aspect of Smule can be approached when one carries out a duet recording in the karaoke application. The duo experience leads to the socalled "collaborations" or "collab": a recorded song merging the vocals of two (or more) singers, or (but more rarely) the vocals with a tune played on the piano or guitar applications. But is it justified to talk about collaboration? The two singers indeed never work together. They do their singing job independently of each other. At best, the second singer adapts his or her singing to the vocals of the first one, sometimes harmonizing or answering to some words the first singer might have said. We have also seen that togetherness is sometimes feigned, when the singers seem to look at each other, but it is not achieved. Singing together is therefore not realised. Smule karaoke singing, as well as Magic Guitar or Piano playing, remain a solitary practice.

As we have seen before, the LiveJam feature can provide this missing simultaneity for people to sing together. There - but only there - Smule karaoke singing can regain something of a social experience: people joining together and taking part in a common activity. Communication is limited to the frame of the phone's camera for the singers, and to the chat discussion for their audience. But despite the distance between participants, their anonymous pseudonyms and profile pictures, social interaction does take place.

In an ontology of common sense, one gives value to the widespread discourses and considers that things are as we say they are in our everyday life (Ruta 2013; Rosenfled \& Jaquet 2014). However, the discourses examined here cannot count as common discourse, bearing a truth value.

\footnotetext{
${ }^{22}$ This video is available on YouTube: https://www.youtube.com/watch?v=kfrONZjakRY (accessed in February 2020).
} 
They are promotional texts and not the words generally spoken by Smule users. Moreover, they speak about very recent things; the applications have just been created. It is not something that is well known by everyone, no matter their situation in space and time in the world. For this reason, we cannot assign them a truth value. Therefore, it is legitimate to question these discourses.

Let us continue with the second value often stated in discourses around Smule: "authenticity" in social music making is what Smule claims to provide and develop. Smith declared for the magazine The Guardian in 2015: "I think people want something fresh and authentic. They want it to be real"23. Smule's karaoke setting is indeed very convincing. LiveJam allows people to see each other through their phones' cameras and to sing together. However, in duet singing, the two singers never actually sing together. Additionally, connecting with people through a social network, applying voice treatment effects to a recording, do not correspond to what one commonly calls "authenticity". The "real" experience remains virtual. This contradiction born by Smule comes even more to light in the presentation video of Magic Guitar $^{24}$. The voice-over boasts the fact that "Guitar brings a special human element", on the grounds that Magic Guitar players can accompany vocalists and connect with singers to collaborate further. After a brief presentation of the application, the video shows a group of young and happy people sitting together in a casual setting; one of them grabs a guitar and they start singing together. "It is about people making music together", says the voice-over. But this is exactly what does not happen with Smule: people strumming a real guitar and singing together - being all in the same place on the same time.

\footnotetext{
${ }^{23}$ Dredge 2015.

24 https://www.smule.com/apps (accessed in February 2020). The application Magic Guitar is by the end of 2020 not supported by Smule anymore.
} 


\section{Conclusion}

Smule offers applications allowing everyone to sing karaoke, play smartphone adaptations of the piano and the guitar, and share video recordings with the network. Not only do these applications offer new ways to indulge in entertainment activities, but they also create new musical practices and objects. A new sort of karaoke singing appears. With Smule, it becomes a solitary practice, accessible anywhere and anytime, where "being together" is most of the time not achieved. Togetherness is realised in the LiveJam feature through audio and video communication, and through a written chat for the audience. Moreover, singing karaoke on Smule is not only a fleeting entertainment, but also an activity oriented towards the production of edited recordings in order to share them on the social network. Therefore, the new musical practice emerging with Smule adds to karaoke singing the production of video recordings.

These karaoke recordings are new musical artifacts. They are music recordings, made of one or several vocals, possibly processed and edited, added up to a backing track. It is therefore a cover of a song, and sometimes a collective one. But most importantly, the utilisation of these recordings is new: they become the building blocks of a social network. Recordings become the main data people share with each other, comment, and like. They are the main argument for people to connect with each other as they build the identity of Smule singers. Musical videos on social networks are not specific to Smule, but in Smule, they really are the key element of the social network. Some professional singers or artists at the start of their career understood the potential of this network and used it to attract fans and gain popularity, especially through making their own songs available in the feature 'Sing with the artist'.

Last but not least, we have shown that the Smule applications, developed for entertainment, do not fully accomplish what they are promised to do in the discourses surrounding them and issued by their creators. Authenticity 
and social experience in music making are not achieved as they are said to be, and Magic Guitar and Magic Piano are closer to video games than musical instruments. Although Smule does not provide the authentic social experience it is claimed to create, it is nonetheless able to delight its users with its musical and play affordances, and successfully meets the desires of a lot of music enthusiasts.

\section{References}

ARBO A. (2010), “Qu'est-ce qu'un 'objet musical' ?”, in Les Cahiers philosophiques de Strasbourg, 28, pp. 225-247.

ARBO A. and RUTA M. (eds.) (2014), Ontologie musicale: perspectives et débats, Hermann, Paris.

BOYD D. M. and ELLISON N. B. (2007), "Social Network Sites: Definition, History, and Scholarship", Journal of Computer-Mediated Communication 13, 1, pp. 210-230.

DAVIES D. (2011), Philosophy of the Performing Arts. Foundations of the philosophy of the arts 4, Wiley-Blackwell, Chichester, West Sussex; Malden, MA.

ID. (2001), Musical works and performances: a philosophical exploration, Clarendon Press, Oxford.

DREDGE, S. (2015), "Smule: the social music app that lets fans sing karaoke with Jessie J", in The Guardian, 23 ${ }^{\text {rd }}$ June; URL:

https://www.theguardian.com/technology/2015/jun/23/smule-appssocial-music-network-jessie-j

ID. (2015), "Smule talks music apps, Jessie J, subscriptions and songwriters", in Musically, $2^{\text {nd }}$ July; URL: https://musically.com/2015/07/02/smulemusic-apps-jessie-j-subscriptions/

GOODMAN N. (1976), Languages of art: An approach to a theory of symbols, Hackett publishing. 
FISCHER-LICHTE E. (2008), The transformative power of performance: a new aesthetics, Routledge, New York.

GODLOVITCH S. (1998), Musical Performance: a Philosophical Study, Routledge, London - New York.

MITSUI T. and SHŪHEI H. (eds.) (1998), Karaoke around the world: global technology, local singing, Routledge, London - New York.

POUIVET R. (2010), Philosophie du rock: une ontologie des artefacts et des enregistrements, Presses Universitaires de France, Paris.

ROSENFLED S. A. and JAQUET C. (2014), Presses Universitaires de Rennes, Rennes, Le sens commun : histoire d'une idée politique.

RUTA M. (2013), “Is there an Ontological Musical Common Sense?”, in Aisthesis. Pratiche, linguaggi e saperi dell'estetico 6, 3 (Special Issue “Ontologie musicali” eds. A. Arbo and A. Bertinetto), pp. 117-125.

TANAKA A. and Bongers, B. (2003), "Global String”, in Proceedings of the Cast01 Conference, pp. 177-181.

WANG Ge. (2014), "The world is your stage: making music on the iPhone", in Oxford Handbook of Mobile Music Studies, Sumanth Gopinath and Jason Stanyek (éds.), vol. 2, Oxford University Press, New York, pp. 487-504.

WANG Ge, et al. (2009), "Smule = Sonic Media: An Intersection of the Mobile, Musical, and Social", in: Proceedings of the International Computer Music Conference, ICMC, Montreal, pp. 283-286. 